\title{
Reconstruction of a Large Upper Lip Defect with Severe Associated Injuries by the Combination of the Kazanjian and Abb é Flaps
}

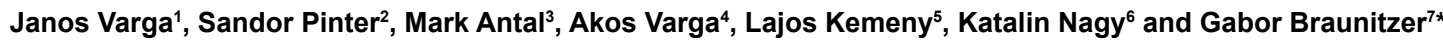 \\ ${ }^{1}$ Faculty of Medicine, Department of Dermatology and Allergy, Division of Aesthetic and Dermatologic Surgery, University of Szeged, Hungary \\ ${ }^{2}$ Faculty of Medicine, Department of Traumatology, University of Szeged, Hungary \\ ${ }^{3}$ Faculty of Dentistry, Department of Aesthetic and Operative Dentistry, University of Szeged, Hungary \\ ${ }^{4}$ Faculty of Medicine, University of Szeged, Hungary \\ ${ }^{5}$ Faculty of Medicine, Department of Dermatology and Allergology, University of Szeged, Hungary \\ ${ }^{6}$ Faculty of Dentistry, Department of Oral Surgery, University of Szeged, Hungary
}

\begin{abstract}
Upper lip defects caused by animal bites can result in serious oral and facial functional compromise. The management of such large defects in a way that an optimal functional and cosmetic outcome is reached remains a major reconstructive challenge. We present the upper lip reconstrucion of a 57-year-old woman who was attacked by her dog. The attack caused severe scalp and facial injuries, including a large upper lip defect. After initial trauma treatment, the lip defect was reconstructed by the combination of the Kazanjian and Abbé flaps. No venous circulation defect, wound healing problems or other complications were detected. After three months, sensory function of the area returned, and after 6 months the movements of the lip were satisfactory, the patient was able to pucker the lips, open the mouth and to eat. Beyond that, a cosmetically acceptable outcome was reached, so that the psychosocial reintegration of the patient was not at risk.We propose that combination of the Kazanjian and Abbe flaps offers an excellent alternative for the reconstruction of wide or total lip resections.
\end{abstract}

\section{Introduction}

Defects of the lips and the perioral area result mostly from malignancies, birth defects or trauma. Upper lip defects caused by dog bites can result in serious functional compromise in terms of oral competence, facial expression, speech, diet, denture- and cutlery use, and sensation. The management of large defects remains a significant reconstructive challenge, requiring meticulous preoperative planning and surgical technique to optimize the functional and cosmetic outcome. The upper lip presents a uniquely complex problem for the facial plastic surgeon because of its prominent location, elegant form, and important functions. The main goals of reconstruction remain the restoration of oral competence, the maintenance of oral opening, and the restoration of normal anatomic relations so that both the active (smile) and passive (form) cosmetic outcome is acceptable.

Small, full-thickness defects involving approximately one fourth to one third of the lip can usually managed by primary closure. The width of such defects is usually less than $2 \mathrm{~cm}[1,2]$. Whenever possible, local tissue should be used to minimize donor site morbidity and for the best overall tissue color and texture match $[2,3]$. In some cases the size of the defect makes it necessary to use myocutaneous or free flap by microvascular technique. If the defect involves $1 / 3-2 / 3$ of the lip, it can be managed by a cross-lip flap, like Abbé or Estlander [1,4], circular rotational flap, such as Karapandzic or Gillies [1,5], nasolabial flap [6] or the Kazanjian reverse flap [7]. In the case of larger defects, a complete reconstruction poses a major challenge. If about $75 \%$ of the remaining lip is intact, reconstruction can be attempted by using tissue from the remaining lip. For multistep reconstructive procedures, combined local flaps are used. The initial reconstruction, such as an expanded Karapandzic flap will restore the oral sphincter $[1,8,9]$. Subsequently, the cross-lip flap can be used to restore symmetry and volume [8]. The modified version of this method, the bilobed flap supplemented by a Karapandzic flap has been used to reconstruct lower lip defects at a success rate over $80 \%[1,3]$. Distant free flaps using microvascular techniques can also be used as well as advancement myocutaneous flaps. The most commonly used free tissue transfer is the free radial forearm flap, which is frequently used with the tendon of the long palmar muscle to support the lip $[1,10]$. This is an innervated flap, as the nerve within the flap (the lateral antebrachial cutaneous nerve) can be reconnected to the mental nerve or to the inferior alveolar nerve. This is a suitable method to repair total or near total lip defects. Other free flaps, such as a gracilis muscle free flap [10] or a free temporal scalp flap can also be used [11]. Here we report a case with a large lip defect and extremely serious associated injuries due to a dog attack, and the process of reparation by a combination of carefully selected methods.

\section{Case Report}

A 57-year-old female patient was attacked by her dog in her home. The patient suffered serious scalp and facial injuries involving the left side of the face, the nose, the eyes, the ears, and the upper lip (Figure 1). She required cardiopulmonary resuscitation in the field.

The patient was admitted to the intensive care unit of the University

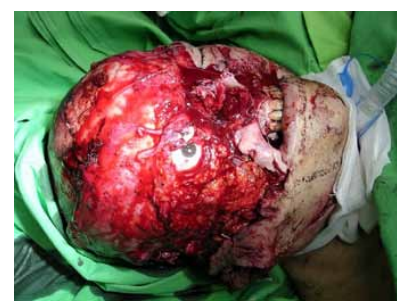

Figure 1: The patient after the attack, in the Emergency Unit.

*Corresponding author: Gabor Braunitzer, Faculty of Dentistry, Department of Oral Surgery, University of Szeged, 6720 Szeged, Tisza Lajos krt. 64, Hungary, Tel: +36 62545 283; Fax: +36 62545 282; E-mail: braunitzer.gabor@gmail.com

Received March 26, 2013; Accepted May 30, 2013; Published June 07, 2013

Citation: Varga J, Pinter S, Antal M, VargaA, Kemeny L, et al. (2013) Reconstruction of a Large Upper Lip Defect with Severe Associated Injuries by the Combination of the Kazanjian and Abbé Flaps. Surgery Curr Res 3: 132. doi:10.4172/21611076.1000132

Copyright: $\odot 2013$ Varga J, et al. This is an open-access article distributed under the terms of the Creative Commons Attribution License, which permits unrestricted use, distribution, and reproduction in any medium, provided the original author and source are credited. 
Citation: Varga J, Pinter S, Antal M, Varga A, Kemeny L, et al. (2013) Reconstruction of a Large Upper Lip Defect with Severe Associated Injuries by the Combination of the Kazanjian and Abbé Flaps. Surgery Curr Res 3: 132. doi:10.4172/2161-1076.1000132

Page 2 of 4

Hospital of Szeged, Hungary, and after 42 days of treatment, she was transferred to our unit in a condition shown in Figure 2. Approximately $70 \%$ of the upper lip was missing. Scar tissue developed at the lateral edges and it became attached to the adjacent tissue. The upper teeth were exposed and the oral mucosa was dry and painful. Nutrition and speech were difficult and painful for the patient. The tracheostoma prepared for the purposes of artificial ventilation during the period of intensive care was closed and the wound healed well. The patient also had a jejunostomy, prepared as part of the emergency management procedures. This was maintained for the duration of the inpatient treatment. In the first phase of reconstruction, the skull was covered by a microvascular flap of the greater omentum, and a right facial arteryretromandibular vein end-to-end anastomosis was prepared. The arteries of the left face were not utilized so as to avoid damage to the remaining intact facial tissues. Subsequently, we began to reconstruct the upper lip.

Several methods are known for the reconstruction of upper lip defects, such as the Abbé flap,the reversed Estlander flap, the Karapandzic flap, Kazanjian's lower facial flap, and the Webster flap combined with Abbé flap. In cases involving large upper lip defects complicated by damages of the comissure, it is difficult to choose an appropriate method for reconstruction, and operative planning is not less challenging. In our case, the extent of the upper lip defect was over $70 \%$ and the left comissure was also missing. In this sense, it can be said that this case was surgically more challenging than larger injuries (like complete degloving) without significant tissue loss [12]. After the initial trauma treatment period, the lip defect was reconstructed with a combination of two methods. The partial lack of arteries and serious damage of the surrounding soft tissue posed extra difficulty. Since the available options for reconstruction were limited, after careful consideration, the combination of Kazanjian and Abbé flaps was chosen.

First, a Kazanjian flap was rotated from the left lower lip area to repair the upper lip defect. An incision was made parallel to the mentolabial and nasolabial lines. The skin and subcutaneous tissue were harvested and care was taken that the nerves and vessels at the lateral edge were preserved. The fibers of the orbicular oris muscle were detached on the right side. After identifying the fibers, they were reconnected in their original position. The closure of the defect was done by layers after appropriate muscular reconnection. The repaired upper lips made it possible to cover the teeth, oral nutrition was achievable and the patient was able to close her mouth again (Figure 3).

In the second stage of the lip reconstruction, cross-lip flap (Abbé) was used to restore the symmetry and volume of the upper and lower lips (Figure 4).

During the treatment, microstoma developed, which was corrected by commisurotomy and mucosa plasty in the final phase of the series of operations. No venous circulation defect, wound healing problems or other complications were detected. After three months, sensory function of the area returned and after 6 months, the movements of the lip were intact, the patient was able to pucker the lips, open the mouth and to eat.

\section{Discussion}

The lips play a key role in facial expression, speech, and food intake. For these, normal morphology, consisting of skin, musculature and mucous membranes, as well as intact sensory and motor functions are all essential. Thus, the reconstruction of large injuries and defects poses a major challenge. Local and free flaps can be used, which may be

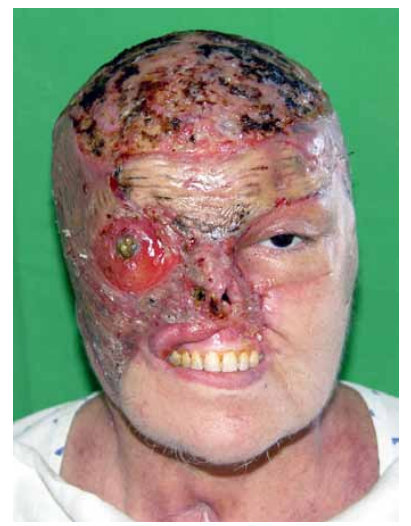

Figure 2: The patient after the first stage of trauma management, before reconstruction.

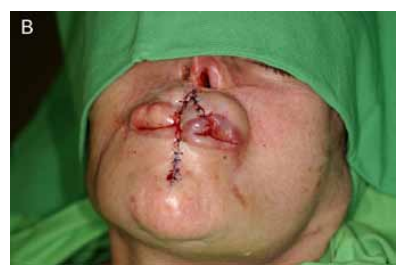

Figure 3: Immediate postoperative status after the Kazanjian (A) and Abbé (B) procedures.

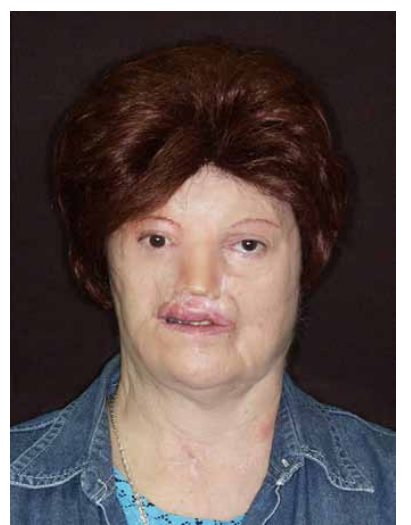

Figure 4: The outcome: an esthetically acceptable status.

classified according to whether they use solely the remaining lip tissue or the surrounding tissues also [8,13-16]. Ultimately, it is the surgeon's responsibility to select the most appropriate procedure in each case. Perhaps the best-known methods are the Abbé cross-flap, Estlander and Gilles flaps and their modifications $[13,15,16]$.

The choice of method often depends on the extent of the defect. If the size of the defect is up to $70-80 \%$ of the lip, it can usually be repaired by using the remaining lip tissue. In case of larger defects additional tissue is required. The use of flaps to reconstruct lip defects requires an immense knowledge of the local vasculature. New flaps for surgery around the mouth can be devised if the surgeon knows the distribution of the perioral arterial branches [6,17-19]. Major branches of the facial artery in the upper lip and nose have been investigated by Nakajima et 
Citation: Varga J, Pinter S, Antal M, Varga A, Kemeny L, et al. (2013) Reconstruction of a Large Upper Lip Defect with Severe Associated Injuries by the Combination of the Kazanjian and Abbé Flaps. Surgery Curr Res 3: 132. doi:10.4172/2161-1076.1000132

al., and the anatomical variations were classified into three types on the basis of the anatomy of the lateral nasal artery, which was determined as an artery running toward the alar base [17]. In 88 percent of the cases, the facial artery bifurcated into the lateral nasal artery and superior labial artery at the angle of the mouth. In 8 percent, the facial artery became an angular artery after branching off into the superior labial artery and the lateral nasal artery sequentially. In 4 percent, the facial artery became an angular artery after branching off into the superior labial artery, and it was only then that the lateral nasal artery branched off from the superior labial artery.

The Karapandzic flap is a reliable technique that offers consistently good functional and aesthetic outcomes for lip defects [8,9]. The Karapandzic reconstruction of lip defects is a versatile, anatomically sound, physiologically and cosmetically acceptable method [7]. Because these myocutaneous advancement flaps have intact nerve and vascular supply, the physiologic functions for speech and food processing are quickly restored, in stark contrast to many other major lip reconstruction techniques. The most common complication noted in connection with the use of Karapandzic labioplasty have been microstomia $[7,9,11,14,16]$ and that this flap can also cause rounding of the corner of the mouth, which compromises the aesthetic result. The oral stoma is of a reduced circumference in most cases but usually does not lead to any functional compromise in terms of oral competence, facial expression, speech, diet, denture- and cutlery use, and sensation. The aesthetic outcome is considered excellent/good in $85 \%$ of cases [8].

An also known, but relatively rarely used reconstructive technique is the transposed nasolabial island flap or gate-flap, which was first introduced by Fujimori [20]. This method enables the surgeon to close very large defects of the lip and since the flaps contain muscle the functional and cosmetic results are better than those achieved with traditional advancement flaps. The method restores the oral sphincter, yielding acceptable aesthetic results and avoiding microstomy at the same time [21-27]. However, in the presented case, the extreme extent of the facial injury and the lack of soft tissues suitable for reconstructive purposes ruled this technique out.

When using a distant or free lap, it is difficult to reconstruct the oral sphincter and the flap usually does not match the characteristics visible of the face. The donor site may develop some morbidity and the operation takes longer. A microvascular anastomosis is necessary and the time for healing and hospitalization might be longer.

In cases of total lip reconstruction, wound hypertrophy, sensory loss, microstomy, shape deformities, loss of the gingivobuccal sulcus and difficulties with wearing a prosthesis/ dentures can all be complications $[4,28]$.

The Kazanjian flap is a well-defined and safe method, suitable for the reconstruction of upper and lower lip defects. The problems usually seen with free flaps and microvascular flaps can be avoided by using this method. This flap, combined with the Abbé flap seems to be an excellent method to reconstruct wide or total lip resection.

\section{Conclusions}

In our case, the extent of the upper defect was over $70 \%$ after the injury. After reconstructive surgery, because of the limited availability of intact and usable surrounding tissues the opening of the mouth was slightly limited. The microstomy was corrected by comissurotomy, which provided acceptable size both in cosmetic and functional respects. A wide range of lip movements, puckering, food intake, and speech were all fully restored. No complications occurred during the postoperative period. The good aesthetic outcome made the full psychosocial rehabilitation of the patient possible.

The oral sphincter was reconstructed by Kazanjian neurovascular myocutaneous flap, while the volume and the symmetry between the upper and lower lip was restored by Abbé cross-flap. The results were acceptable in both functional and aesthetic respects. Therefore, we recommend this combined method for the reconstruction of large upper lip defects associated with serious injuries.

\section{References}

1. Anvar BA, Evans BC, Evans GR (2007) Lip reconstruction. Plast Reconstr Surg 120: $57 \mathrm{e}-64 \mathrm{e}$.

2. Coppit GL, Lin DT, Burkey BB (2004) Current concepts in lip reconstruction Curr Opin Otolaryngol Head Neck Surg 12: 281-287.

3. Bocchi A, Baccarani A, Bianco G, Castagnetti F, Papadia F (2003) Double V-Y advancement flap in the management of lower lip reconstruction. Ann Plast Surg 51: 205-209.

4. Krunic AL, Weitzul S, Taylor RS (2005) Advanced reconstructive techniques for the lip and perioral area. Dermatol Clin 23: 43-53, v-vi.

5. McCarn KE, Park SS (2005) Lip reconstruction. Facial Plast Surg Clin North Am 13: 301-314, vii.

6. Pinar YA, Bilge O, Govsa F (2005) Anatomic study of the blood supply of perioral region. Clin Anat 18: 330-339.

7. Clairmont AA (1977) Versatile Karapandzic lip reconstruction. Arch Otolaryngo 103: 631-633.

8. Ethunandan M, Macpherson DW, Santhanam V (2007) Karapandzic flap for reconstruction of lip defects. J Oral Maxillofac Surg 65: 2512-2517.

9. Karapandzic M (1974) Reconstruction of lip defects by local arterial flaps. Br Plast Surg 27: 93-97.

10. Kushima H, Iwasawa M, Kiyono M, Ohtsuka Y, Hataya Y (1997) Functional reconstruction of total lower lip defects with a radial forearm free flap combined with a depressor anguli oris muscle transfer. Ann Plast Surg 39: 182-185.

11. Calhoun KH (1992) Reconstruction of small- and medium-sized defects of the lower lip. Am J Otolaryngol 13: 16-22.

12. Catunda IS, de Medeiros MF, Santos LA, Melo AR (2012) An impressive case of complete traumatic maxillofacial degloving. Int $\mathrm{J}$ Oral Maxillofac Surg 41 344-349.

13. Baker SN (1995) Local Flaps in Facial Reconstruction. St. Louis: Mosby-Yea Books.

14. Jabaley ME, Orcutt TW, Clement RL (1976) Applications of the Karapandzic principle of lip reconstruction after excision of lip cancer. Am J Surg 132: 529 532

15. McGregor I, McGregor, F (1986) Cancer of the Face and Mouth. Edinburgh: Churchill Livingstone.

16. Smith PG, Muntz HR, Thawley SE (1982) Local myocutaneous advancement flaps. Alternatives to cross-lip and distant flaps in the reconstruction of ablative lip defects. Arch Otolaryngol 108: 714-718.

17. Nakajima H, Imanishi N, Aiso S (2002) Facial artery in the upper lip and nose: anatomy and a clinical application. Plast Reconstr Surg 109: 855-861.

18. Park C, Lineaweaver WC, Buncke HJ (1994) New perioral arterial flaps: anatomic study and clinical application. Plast Reconstr Surg 94: 268-276.

19. Rohrich RJ, Muzaffar AR, Gunter JP (2000) Nasal tip blood supply: confirming the safety of the transcolumellar incision in rhinoplasty. Plast Reconstr Surg 106: $1640-1641$

20. Fujimori R (1980) "Gate flap" for the total reconstruction of the lower lip. Br Plast Surg 33: 340-345

21. Baker SR (1990) Regional flaps in facial reconstruction. Otolaryngol Clin North Am 23: 925-946.

22. Glicenstein J, Guero S (1990) Nasolabial musculocutaneous island flap. Ann Chir Plast Esthet 35: 112-116.

23. Hurwitz DJ (1990) Composite upper lip repair with V-Y advancement flaps. Plast Reconstr Surg 85: 120-122. 
Citation: Varga J, Pinter S, Antal M, Varga A, Kemeny L, et al. (2013) Reconstruction of a Large Upper Lip Defect with Severe Associated Injuries by the Combination of the Kazanjian and Abbé Flaps. Surgery Curr Res 3: 132. doi:10.4172/2161-1076.1000132

24. Ortner R (1990) Pedicle flap-plasties of defects following tumor resection of the upper lip. Z Hautkr 65: 543-547.

25. Panje WR (1982) Lip reconstruction. Otolaryngol Clin North Am 15: 169-178.

26. Yotsuyanagi T, Yokoi K, Urushidate S, Sawada Y (1998) Functional and aesthetic reconstruction using a nasolabial orbicularis oris myocutaneous flap for large defects of the upper lip. Plast Reconstr Surg 101: 1624-1629.
27. Zide B (1986) Deformities of the Lips and Cheeks. In: McCarthy J (ed.). Plastic Surgery. Philadelphia: WB Saunders.

28. Eguchi T, Nakatsuka T, Mori Y, Takato T (2005) Total reconstruction of the upper lip after resection of a malignant melanoma. Scand J Plast Reconstr Surg Hand Surg 39: 45-47. 